\title{
COMPOSIÇÃO QUÍMICA DA CHUVA E APORTE ATMOSFÉRICO NA ILHA GRANDE, RJ
}

\section{Patricia Alexandre de Souza, William Zamboni de Mello* e Juan Maldonado}

Departamento de Geoquímica, Instituto de Química, Universidade Federal Fluminense, Outeiro de São João Batista, s/n, 24020-007 Niterói - RJ, Brasil

\section{Heitor Evangelista}

Departamento de Biofísica e Biometria, Instituto de Biologia Roberto Alcântara Gomes, Universidade Estadual do Rio de Janeiro, Av. São Francisco Xavier, 524, 20550-900 Rio de Janeiro - RJ, Brasil

Recebido em 8/3/05; aceito em 24/8/05; publicado na web em 16/2/06

\begin{abstract}
RAINWATER CHEMISTRY AND ATMOSPHERIC DEPOSITION AT ILHA GRANDE, RJ. Wet $(\mathrm{n}=21)$ and dry $(\mathrm{n}=23)$ deposition samples were collected from March to September 2002 at the southern coast of Ilha Grande. Rainwater $\mathrm{pH}$ varied from 4.3 to 6.3 and ionic concentrations (in $\mu \mathrm{mol} \mathrm{L}{ }^{-1}$ ) decreased in the order $\mathrm{Cl}^{-}>\mathrm{Na}^{+}>\mathrm{Mg}^{2+}>\mathrm{SO}_{4}{ }^{2-}>\mathrm{NO}_{3}{ }^{-} \sim \mathrm{NH}_{4}^{+}>\mathrm{K}^{+} \sim \mathrm{H}^{+}>\mathrm{Ca}^{2+}$. Scavenging of sea-salt aerosols was the major source of $\mathrm{Cl}^{-}, \mathrm{Na}^{+}, \mathrm{Mg}^{2+}$, and $\mathrm{Ca}^{2+}$. Half of total $\mathrm{SO}_{4}^{2-}$ was non-sea-salt $\mathrm{SO}_{4}^{2-}$. Total deposition fluxes of $\mathrm{NH}_{4}^{+}, \mathrm{NO}_{3}^{-}$, and non-sea-salt $\mathrm{SO}_{4}{ }^{2-}$ were respectively $9.3,17.8$, and $16.0 \mathrm{~mol} \mathrm{ha}^{-1}$ month ${ }^{-1}$.
\end{abstract}

Keywords: wet deposition; dry deposition; air pollution.

\section{INTRODUÇÃO}

A composição química da água da chuva é uma combinação da composição química das gotículas que formam as nuvens e das substâncias que se incorporam às gotas de chuva durante a precipitação. Sendo assim, a água da chuva, de certa forma, retrata as características da massa de ar, no que diz respeito ao conteúdo de partículas e gases solúveis em água, através da qual atravessam as gotas de chuva durante a precipitação $0^{1,2}$. Evidência disso é a variação da composição química da água da chuva em relação ao tempo, que se observa no decorrer de um evento de precipitação ${ }^{3}$. Outra evidência é a relação inversa que há entre o total de íons dissolvidos e a quantidade de chuva precipitada, sugerindo que a maior parte dos íons presentes na água da chuva se incorpora a ela durante a precipitação, processo conhecido como remoção abaixo da nuvem ("below-cloud removal")

As deposições atmosféricas constituem um dos principais mecanismos da ciclagem e redistribuição dos vários elementos químicos sobre a superfície do planeta, exercendo, portanto, um papel fundamental nos processos biogeoquímicos continentais e costeiros. O conhecimento quantitativo e qualitativo das deposições atmosféricas é relevante para o entendimento dos ciclos biogeoquímicos de elementos e da influência das atividades antrópicas nestes processos. As águas costeiras, um dos mais valiosos e vulneráveis habitats da Terra, estão sujeitas à influência do aporte de nutrientes não só através dos rios e águas subterrâneas, mas também da atmosfera. Por ex., o elevado aporte de nutrientes via atmosfera pode trazer como conseqüência o aumento da população fitoplanctônica, bem como alteração na distribuição das diferentes espécies destes organismos ${ }^{7}$. Estudos recentes apontam para potenciais conseqüências do aumento do aporte atmosférico de nitrogênio $(\mathrm{N})$ em ecossistemas tropicais terrestres. No caso, se o aporte atmosférico de $\mathrm{N}$ superar sua demanda biológica (produção primária), o sistema passa a perder a capacidade de reter $\mathrm{N}$, provocando o aumento da transferência de $\mathrm{N}$ para águas subterrâneas e rios, bem como o aumento das emissões para a atmosfera de óxidos de

*e-mail: zamboni@geoq.uff.br
$\mathrm{N}$, tais como óxido nítrico $(\mathrm{NO})$ e óxido nitroso $\left(\mathrm{N}_{2} \mathrm{O}\right)^{8}$. Outra consequiência é o aumento da acidez do solo provocada pelo aumento da taxa de nitrificação, ou seja, oxidação do íon amônio $\left(\mathrm{NH}_{4}^{+}\right)$ pelas bactérias nitrificantes, visto que para cada $\mathrm{NH}_{4}^{+}$oxidado formam-se dois íons $\mathrm{H}^{+}\left(\mathrm{NH}_{4}^{+}+2 \mathrm{O}_{2} \rightarrow 2 \mathrm{H}^{+}+\mathrm{NO}_{3}^{-}+\mathrm{H}_{2} \mathrm{O}\right)$.

$\mathrm{O}$ presente estudo foi realizado na costa sul da Ilha Grande (RJ) e teve os seguintes objetivos: conhecer a composição química da água da chuva, identificar alguns dos fatores atuantes no controle da composição química da água da chuva, e estimar os fluxos atmosféricos dos íons majoritários sob as formas de deposição úmida e deposição seca, individualmente. Estudos anteriores sobre os aportes atmosféricos de nutrientes e de alguns metais na costa sul do estado do Rio de Janeiro abordaram somente a deposição total, i.e., a deposição úmida e deposição seca combinadas?

\section{ÁREA DE ESTUDO}

O estudo foi realizado próximo ao Centro de Estudos Ambientais e Desenvolvimento Sustentável (CEADS) da Universidade do Estado do Rio de Janeiro (UERJ), localizado na Vila Dois Rios, na costa sul da Ilha Grande. O coletor foi instalado a aproximadamente $80 \mathrm{~m}$ a leste do CEADS e $100 \mathrm{~m}$ de distância do mar (2310'51,0" S; 44¹1'39,1”W). A Ilha Grande está situada na baía da Ilha Grande e integra o município de Angra dos Reis. É a terceira maior ilha brasileira, possui uma área de quase $190 \mathrm{~km}^{2} \mathrm{e}$ está a aproximadamente $100 \mathrm{~km}$ do centro da cidade do Rio de Janeiro e $250 \mathrm{~km}$ do centro da cidade de São Paulo. Possui diversos ecossistemas, predominando a floresta ombrófila densa (das terras baixas, submontanas e montanas), mas também restingas e manguezais. A precipitação anual é de aproximadamente $1500 \mathrm{~mm}$ e a temperatura média anual é de $22,5^{\circ} \mathrm{C}^{10}$. A face norte da ilha é voltada para o continente enquanto a sul para o oceano, ambas separadas por uma cadeia de montanhas, onde se destacam os Picos da Pedra d'Água e do Papagaio, com 1035 e 982 m de altitude, respectivamente. O maior distrito da Ilha Grande é a Vila Abraão (população 2.200 habitantes), situada na costa norte da ilha, e constitui o maior porto de chegada de moradores e turistas.

A Ilha Grande está sujeita à influência de poluentes atmosféri- 
cos gerados nos grandes centros urbanos e industriais dos estados do Rio de Janeiro e, possivelmente, São Paulo. Em estudo realizado na Vila Dois Rios, Maldonado ${ }^{10}$ observou que as concentrações de carbono elementar foram, em média, de 4 a 5 vezes maiores quando os ventos sopravam do continente que quando sopravam do quadrante sul (oceânico). Além disso, observou incrementos anômalos nas concentrações de carbono elementar durante os meses de queimadas.

\section{PARTE EXPERIMENTAL}

\section{Coleta de amostras}

O período de amostragem foi de 17/3 a 25/9/2002, quando foram coletadas 21 amostras de deposição úmida e 23 amostras de deposição seca. As coletas foram efetuadas por meio de um coletor automático Graseby/GMW modelo APS 78-100. O coletor consiste de dois compartimentos, um para coleta da deposição úmida (água de chuva exclusivamente) e outro para coleta da deposição seca (predominantemente partículas depositadas pela ação gravitacional). $\mathrm{O}$ equipamento contém um sensor para controle de abertura e fechamento destes compartimentos.

Em menos de 24 h após o término dos eventos de precipitação, as amostras de água de chuva foram transferidas para frascos de polietileno (Nalgon) de $500 \mathrm{~mL}$ e o volume total de chuva foi registrado para posterior cálculo da precipitação acumulada no período. Para recolhimento da deposição seca, efetuada uma vez a cada sete dias, uma alíquota de aproximadamente $80 \mathrm{~mL}$ de água destilada (Fisatom, modelo 525) e desionizada (Permution) (resistividade 1-2 $\mathrm{M} \Omega \mathrm{cm}$ ) foi adicionada ao interior do compartimento de deposição seca. Após cuidadosa agitação manual, a solução foi vertida para o frasco de polietileno de $500 \mathrm{~mL}$. Esse procedimento foi repetido por mais 2 vezes, com iguais volumes, de forma a garantir total remoção do material solúvel. Em seguida, as amostras de água de chuva e de deposição seca (dissolvida em água) foram armazenadas em freezer no CEADS-UERJ, onde foram mantidas congeladas por cerca de 4 semanas e em seguida transferidas para o Laboratório de Biogeoquímica de Ambientes Tropicais, do Departamento de Geoquímica da Universidade Federal Fluminense (UFF), onde foram efetuadas as análises químicas.

É importante ressaltar que, pela falta de equipamentos disponíveis, o pH e a condutividade não foram medidos logo após o recolhimento das amostras na Ilha Grande. Não foram feitos testes de estabilidade das amostras (sob condições de congelamento) no que tange a possíveis alterações na composição química da água da chuva enquanto armazenadas. Quanto a isso, a literatura apresenta resultados de testes, de certa forma, controversos. Galloway e Likens ${ }^{11}$ mostraram que amostras de água de chuva preservadas à $25^{\circ} \mathrm{C}$ durante 7 meses, tanto na presença quanto na ausência de luz, não apresentaram alterações nas concentrações dos íons majoritários, entretanto, em uma amostra armazenada à $-10^{\circ} \mathrm{C}$ houve diminuição na concentração de $\mathrm{NH}_{4}{ }^{+}$. Galloway e Likens ${ }^{11}$ mostraram que o uso de biocidas, como formaldeido, metanol, clorofórmio, tolueno e outros, levaram, de alguma forma, a alterações na composição química da água da chuva. Karlson et al. ${ }^{12}$ mostraram que, em amostras de deposição total (úmida + seca) não filtradas e armazenadas em refrigerador à $4{ }^{\circ} \mathrm{C}$, as concentrações dos íons $\mathrm{Cl}^{-}, \mathrm{NO}_{3}^{-}, \mathrm{SO}_{4}{ }^{2-}, \mathrm{Na}^{+}, \mathrm{K}^{+}$, $\mathrm{Mg}^{2+} \mathrm{e} \mathrm{Ca}^{2+}$ se mantiveram inalteradas por 7 semanas, ao passo que $\mathrm{pH}$, condutividade e $\mathrm{NH}_{4}^{+}$se mantiveram estáveis nos 6-7 primeiros dias que se seguiram à coleta; em 7 semanas, em média, o pH aumentou 0,15 unidades de $\mathrm{pH}$, e a condutividade e $\mathrm{NH}_{4}^{+}$diminuiram, respectivamente, 12 e $25 \%$. Galloway e Likens ${ }^{11}$ sugeriram que, se ácidos orgânicos não forem analisados, amostras de água de chuva e deposição total devem ser coletadas por evento ou no máximo semanalmente; períodos superiores a uma semana aumentam as chances de alteração de sua composição química.

\section{Análises químicas}

Ao chegarem no laboratório na UFF, as amostras foram descongeladas naturalmente até atingirem temperatura ambiente e, em seguida, filtradas em membranas de acetato de celulose (Millipore) com diâmetro de poro de $0,22 \mu \mathrm{m}$. Alíquotas de amostras filtradas foram imediatamente congeladas $\left(\sim-22{ }^{\circ} \mathrm{C}\right)$ para posterior análises dos íons dissolvidos. Medidas de $\mathrm{pH}$ e condutividade foram efetuadas, em alíquotas não filtradas, com equipamentos WTW ("Wissenschaftlich Technische Werkstätten"), modelos pH330 e LF330, respectivamente. O eletrodo de $\mathrm{pH}$ é do tipo combinado e os padrões utilizados para calibração foram de pH 4,00 e 6,86, preparados de acordo com Eaton et al. ${ }^{13}$. As concentrações de $\mathrm{H}^{+}$ foram calculadas a partir dos valores de $\mathrm{pH}$. $\mathrm{O}$ condutivímetro foi calibrado com solução de $1,0 \mathrm{mmol} \mathrm{L}{ }^{-1}$ de $\mathrm{KCl}$, cuja condutividade é de $147 \mu \mathrm{S} \mathrm{cm}^{-1}$ à $25^{\circ} \mathrm{C}^{13}$. Também em alíquotas não filtradas, foi determinado o íon $\mathrm{NH}_{4}^{+}$pelo método de azul de indofenol, um complexo que se forma a partir da reação da amônia com ácido isocianúrico e fenol. A absorbância foi medida em um espectrofotômetro Hitachi, modelo U-1100.

Os ânions $\mathrm{Cl}^{-}, \mathrm{NO}_{3}^{-}$e $\mathrm{SO}_{4}^{2-}$ foram analisados por cromatografia líquida (Shimadzu, modelo LC-10AD) equipada com detector de condutividade (CDD-6A), cuja fase móvel consiste de uma solução de biftalato de potássio $2,4 \mathrm{mmol} \mathrm{L}^{-1}$, a uma vazão de $1,4 \mathrm{~mL}$ $\min ^{-1}$ e sem sistema de supressão. A coluna cromatográfica utilizada foi do tipo Shim-pack IC-A1 $(4,6 \mathrm{~mm}$ x $10 \mathrm{~cm})$, com pré-coluna Shim-pack IC-GA1. O volume (de amostras e padrões) injetado foi de 200 ou $1000 \mu \mathrm{L}$, dependendo das concentrações esperadas com base nos valores das condutividades medidas das amostras. A temperatura de operação da coluna foi de $40{ }^{\circ} \mathrm{C}$. Os cátions $\mathrm{Na}^{+} \mathrm{e}$ $\mathrm{K}^{+}$foram analisados por espectrofotometria de emissão de chama e $\mathrm{Mg}^{2+} \mathrm{e} \mathrm{Ca}^{2+}$, por absorção atômica, em um equipamento Baird Atomic, modelo 4200. Os limites de detecção dos íons analisados foram (em $\left.\mu \mathrm{mol} \mathrm{L}{ }^{-1}\right)$ : $\mathrm{Na}^{+}(1,0), \mathrm{K}^{+}(1,4), \mathrm{Mg}^{2+}(1,0), \mathrm{Ca}^{2+}(0,2)$, $\mathrm{NH}_{4}^{+}(0,2), \mathrm{Cl}^{-}(1,7), \mathrm{NO}_{3}^{-}(0,2)$ e $\mathrm{SO}_{4}^{2-}(0,2)$.

A precisão das análises químicas foi de $\pm 5 \%$. A qualidade dos resultados dos íons $\mathrm{Cl}^{-}, \mathrm{SO}_{4}^{2-}, \mathrm{Na}^{+}, \mathrm{Mg}^{2+}, \mathrm{Ca}^{2+}$ e $\mathrm{K}^{+}$foi verificada também por meio de diluições 1:500 e 1:2000 de água do mar padrão (IAPSO Standard Seawater; salinidade = 34,996; Ocean Scientific International Ltd., UK) em água destilada e desionizada (resistividade 1-2 M $\Omega \mathrm{cm}$ ). Os resultados obtidos deste teste encontraram-se na faixa de $\pm 5 \%$ em relação aos valores esperados para concentrações destes íons em água do $\operatorname{mar}^{14}$.

\section{Cálculo da condutividade}

A condutividade calculada $\left(k_{\text {calc }}\right)$ de cada amostra de água de chuva foi obtida de acordo com a Equação $1^{13}$

$k_{\text {calc }}=k^{o} y^{2}$

onde $k^{o}$ é a condutividade calculada para uma diluição infinita e $y$, o coeficiente de atividade para íon monovalente.

A condutividade calculada para uma diluição infinita é obtida através da Equação 2

$k^{o}=\Sigma\left|z_{i}\right|\left(\lambda_{+\mathrm{i}}^{\mathrm{o}}\right) \mathrm{c}_{\mathrm{i}} 10+\Sigma\left|z_{i}\right|\left(\lambda_{-\mathrm{i}}^{\mathrm{o}}\right) \mathrm{c}_{\mathrm{i}} 10$

onde $\left|z_{i}\right|$ é o valor relativo da carga do íon $i, \lambda_{+\mathrm{i}}^{0}$ e $\lambda_{-\mathrm{i}}^{0}$ são as 
condutâncias equivalentes (em $10^{-4} \mathrm{~m}^{2} \mathrm{~S} \mathrm{~mol}^{-1}$ ) de um cátion $+i$ e um ânion - $i$, e c é a concentração do íon $i$ (em $\left.\mu \mathrm{mol} \mathrm{L}^{-1}\right)$. Os valores das condutâncias equivalentes acham-se compilados em Weast et al. ${ }^{15}$, expressas na unidade apresentada acima. Na Equação (2), com os valores de $c_{i}$ e $\lambda_{i}^{0}$ expressos respectivamente em $\mu$ mol L $L^{-1}$ e $10^{-4} \mathrm{~m}^{2} \mathrm{~S} \mathrm{~mol}{ }^{-1}$, o resultado de $k^{o}$ é obtido em $\mu \mathrm{S} \mathrm{cm}^{-1}$.

$\mathrm{O}$ coeficiente de atividade para íon monovalente pode ser calculado pela Equação de Davies ${ }^{16}$

$\log y=-\mathrm{A} z_{i}^{2}\left\{\left[I^{0,5} /\left(1+I^{0,5}\right)\right]-0,3 I\right\}$

onde $\mathrm{A} \sim 0,5$ e $I\left(\mathrm{em} \mathrm{mol} \mathrm{L}^{-1}\right)$ é a força iônica, calculada pela Equação 4

$I=0,5\left(\Sigma \mathrm{c}_{\mathrm{i}} z_{i}^{2}\right) / 10^{6}$

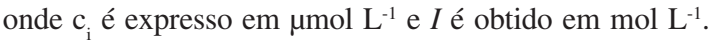

\section{Qualidade analítica}

A avaliação da qualidade dos resultados das análises das amostras de água de chuva foi feita com base na comparação da condutividade medida $\left(k_{\text {med }}\right)$ e a condutividade calculada $\left(k_{\text {call }}\right)$ e no balanço de massa iônica equivalente $(\Delta \mathrm{Ion})$, através das Equações 5 e $6^{17}$ :

$\Delta k(\mathrm{em} \%)=\left[\left(k_{\text {calc }}-k_{\text {med }}\right) \times 100\right] /\left(k_{\text {med }}\right)$

$\Delta \operatorname{Ion}\left(\right.$ em \%) $=[(\Sigma$ ânions $-\Sigma$ cátions $) \times 100] /\left(\sum a ̂ n i o n s ~+\Sigma\right.$ cátions $)$

onde $\Sigma$ ânions e $\Sigma$ cátions representam as somas das concentrações dos ânions e dos cátions.

De acordo com os critérios apresentados por Campos et al. ${ }^{17}$, deverão ser rejeitadas amostras com $k_{\text {med }} \leq 30 \mu \mathrm{S} \mathrm{cm}^{-1}$ cujos $\Delta k$ excederem a faixa de $\pm 30 \%$, bem como aquelas com $k_{\text {med }}>30 \mu \mathrm{S}$ $\mathrm{cm}^{-1}$ cujos $\Delta k$ excederem a faixa de $\pm 50 \%$. Da mesma forma, deverão ser rejeitadas amostras com $I \leq 100 \mu \mathrm{eq} \mathrm{L}^{-1}$ cujos $\Delta \mathrm{Ion}> \pm 50 \%$, bem como aquelas com $I>100 \mu$ eq $\mathrm{L}^{-1}$ cujos $\Delta \mathrm{Ion}> \pm 25 \%$.

\section{RESULTADOS E DISCUSSÃO}

\section{Composição química da água da chuva}

A condutividade elétrica medida nas amostras variou de 12,6 a $222 \mu \mathrm{S} \mathrm{cm}^{-1}$, com média ponderada pelo volume (MPV) de 29,9 $\mu \mathrm{S}$ $\mathrm{cm}^{-1}$ (média aritmética $=41,2 \mu \mathrm{S} \mathrm{cm}^{-1}$; mediana $=20,8 \mu \mathrm{S} \mathrm{cm} \mathrm{cm}^{-1}$ ). Os valores dos coeficientes de atividade $(y)$ variaram de 0,951 a 0,990 , atribuídos às amostras de água de chuva com maior e menor valor de condutividade, respectivamente. A Figura 1 mostra a relação entre os valores da condutividade medida $\left(k_{\text {med }}\right)$ e a condutividade calculada $\left(k_{\text {calc }}\right)$, onde se verifica que a distribuição dos pontos foi bastante próxima à razão $1: 1$. O coeficiente de correlação linear $(r)$ obtido para a relação condutividade medida vs. condutividade calculada (para $\mathrm{n}=21$ ) foi de 1,00. A média aritmética e a mediana dos valores de $\Delta k$ foram, respectivamente, -2 e $-6 \%(\mathrm{n}=21)$. Das 21 amostras de água de chuva analisadas, 20 apresentaram valor de $\Delta k$ na faixa de -20 a $12 \%$. Uma única amostra apresentou $\Delta k=-43 \%$, cuja $k_{\text {med }}$ foi de $14,3 \mu \mathrm{S} \mathrm{cm}^{-1}$. A média aritmética e a mediana dos valores de $\Delta$ Ion foram respectivamente 4 e $5 \%(n=21)$. Vinte amostras apresentaram $\Delta$ Ion entre -13 e $22 \%$. Uma única amostra (a mesma com $\Delta k=$ $-43 \%$ ) apresentou $\Delta \mathrm{Ion}=-38 \%$, cuja força iônica $(I)$ foi $224 \mu \mathrm{eq} \mathrm{L}^{-1}$. Com base nos critérios apresentados por Campos et al. ${ }^{17}$, esta amos- tra foi excluída do conjunto dos dados que serão tratados daqui para frente.

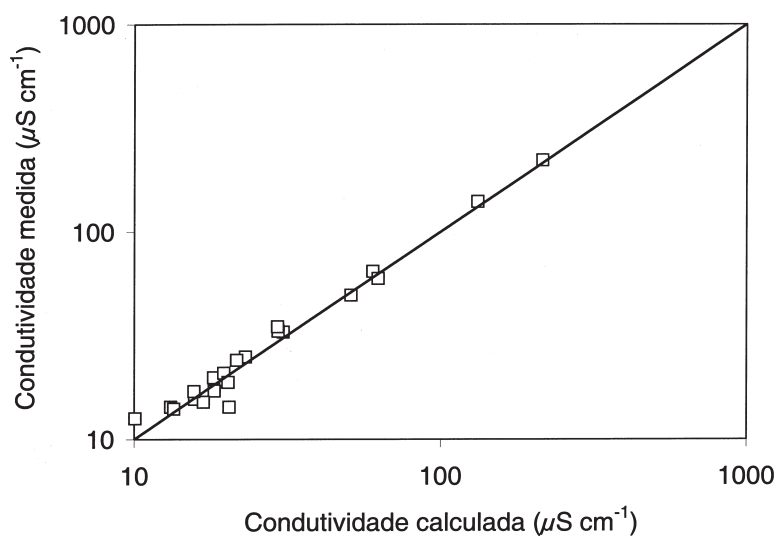

Figura 1. Correlação entre os valores de condutividade medida e calculada para 21 amostras de água de chuva coletadas na Ilha Grande, no período de março a setembro de 2002. A linha contínua representa a relação 1:1

Com base nas concentrações MPV, as somas de cátions ( $\Sigma$ cátions) e de ânions ( ânions) analisados foram respectivamente 214,8 e 225,0 $\mu$ eq $\mathrm{L}^{-1}$, apresentando, portanto, um déficit de cátions de $10,2 \mu \mathrm{eq} \mathrm{L}^{-1}$. Em geral, quando somente os íons inorgânicos são analisados, o que se verifica é que $\Sigma$ cátions é maior que $\Sigma$ ânions, e a explicação para o déficit de ânions é atribuída principalmente aos carboxilatos não analisados. Acetato $\left(\mathrm{CH}_{3} \mathrm{COO}^{-}\right)$e formiato $\left(\mathrm{HCOO}^{-}\right)$estão presentes na água da chuva de florestas tropicais úmidas, apresentando individualmente concentrações médias na faixa de 3 a $9 \mu \mathrm{mol} \mathrm{L}^{-1} 4,18$, e em regiões oceânicas remotas, apresentando individualmente concentrações médias inferiores a $2 \mu \mathrm{mol} \mathrm{L} \mathrm{L}^{-1}{ }^{19}$. Na Região Metropolitana de São Paulo, as concentrações médias de $\mathrm{CH}_{3} \mathrm{COO}^{-}$e $\mathrm{HCOO}^{-}$estão na faixa de 5 a $17 \mu \mathrm{mol} \mathrm{L}{ }^{-1}{ }^{20}$. O déficit médio de cátions de $10,2 \mu \mathrm{eq}$ $\mathrm{L}^{-1}$ verificado nos resultados da Ilha Grande representa 4,5 e 4,7\% da soma dos cátions e soma dos ânions, respectivamente, valores que se encontram na faixa de incerteza dos nossos resultados $( \pm 5 \%)$. Sendo assim, pelo balanço iônico não foi possível se obter uma estimativa do total de carboxilatos presentes nas amostras de água de chuva da Ilha Grande.

A Tabela 1 apresenta a estatística descritiva referente às concentrações dos íons inorgânicos majoritários presentes na água da chuva da Ilha Grande. Os valores de $\mathrm{pH}$ variaram de 4,34 a 6,30. O pH médio, calculado a partir da concentração MPV de $\mathrm{H}^{+}$, foi de 5,22,

Tabela 1. Composição química da água da chuva (concentrações em $\mu \mathrm{mol} \mathrm{L} \mathrm{L}^{-1} ; \mathrm{n}=20$ ) na Vila Dois Rios, costa sul da Ilha Grande, $\mathrm{RJ}$

\begin{tabular}{lrrccc}
\hline & MPV & MA & Mediana & Mínimo & Máximo \\
\hline $\mathrm{pH}$ & 5,22 & 5,05 & 5,29 & 4,34 & 6,30 \\
$\mathrm{H}^{+}$ & 6,0 & 8,9 & 5,1 & 0,5 & 45,7 \\
$\mathrm{Na}^{+}$ & 142,2 & 205,3 & 85,8 & 22,2 & 1435,9 \\
$\mathrm{~K}^{+}$ & 7,1 & 9,8 & 6,0 & 1,3 & 40,0 \\
$\mathrm{Mg}^{2+}$ & 20,2 & 28,7 & 15,8 & 3,4 & 172,1 \\
$\mathrm{Ca}^{2+}$ & 4,6 & 6,3 & 4,0 & 1,8 & 30,5 \\
$\mathrm{NH}_{4}^{+}$ & 9,9 & 12,9 & 10,8 & 0,2 & 58,3 \\
$\mathrm{NO}_{3}^{-}$ & 12,0 & 16,8 & 16,4 & 2,4 & 39,6 \\
$\mathrm{SO}_{4}^{2-}$ & 17,4 & 24,2 & 13,9 & 7,4 & 104,1 \\
$\mathrm{Cl}^{-}$ & 178,2 & 254,4 & 133,3 & 33,3 & 1501,6 \\
\hline
\end{tabular}

MPV - média ponderada pelo volume; MA - média aritmética. 
que corresponde a uma acidez livre de $6,0 \mu \mathrm{mol} \mathrm{L} \mathrm{L}^{-1}$. Em geral, são chamadas de chuvas ácidas aquelas que possuem valores de $\mathrm{pH}$ inferiores a 5,6, valor resultante da ionização parcial do ácido carbônico $\left(\mathrm{H}_{2} \mathrm{CO}_{3}\right)$ em água pura, formado a partir da dissolução do dióxido de carbono $\left(\mathrm{CO}_{2}\right)$ da atmosfera, cuja pressão parcial atualmente é $3,7 \times 10^{-4}$ atm (370 ppm). Na Ilha Grande $65 \%$ dos valores de $\mathrm{pH}$ foram inferiores a 5,6. Entretanto, Galloway et al. ${ }^{21}$ atribuíram o valor 5,0 como o limite inferior de $\mathrm{pH}$ para águas de chuva acidificadas por substâncias originárias de processos naturais. $\mathrm{Na}$ Ilha Grande, quase 30\% dos valores de $\mathrm{pH}$ foram inferiores a 5,0.

As concentrações iônicas apresentaram grandes variações, atingindo valores superiores a uma ordem de grandeza nas razões entre máximos e mínimos. $\mathrm{O}$ íon $\mathrm{NH}_{4}^{+}$foi aquele que apresentou a maior variabilidade. As menores variabilidades ocorreram para os íons $\mathrm{SO}_{4}^{2-}$ e $\mathrm{NO}_{3}^{-}$. Na maior parte dos casos, as médias aritméticas foram superiores às medianas, indicando que as curvas de frequiência dos dados apresentam distribuição assimétrica positiva, o que se deve à influência de valores muito elevados em relação à maioria. As concentrações MPV, em unidade molar, decresceram na seguinte ordem: $\mathrm{Cl}^{-}>\mathrm{Na}^{+}>\mathrm{Mg}^{2+}>\mathrm{SO}_{4}{ }^{2-}>\mathrm{NO}_{3}{ }^{-} \sim \mathrm{NH}_{4}^{+}>\mathrm{K}^{+} \sim \mathrm{H}^{+}$ $>\mathrm{Ca}^{2+}$ (Figura 2). Em média, $80 \%$ da concentração (molar) total de íons inorgânicos dissolvidos na água da chuva da Ilha Grande foram atribuídos aos íons $\mathrm{Cl}^{-}$e $\mathrm{Na}^{+}$. Com base nas concentrações MPV, a razão molar $\mathrm{Cl} / \mathrm{Na}^{+}$foi 1,25 , ligeiramente superior $(7,6 \%)$ à razão $\mathrm{Cl}^{-} / \mathrm{Na}^{+}$na água do $\operatorname{mar}^{14}$.

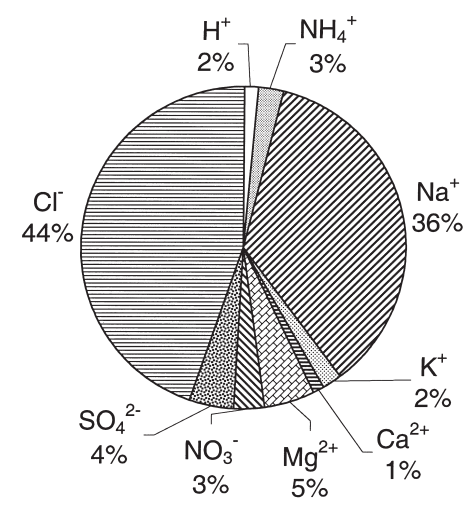

Figura 2. Distribuição percentual dos íons inorgânicos majoritários presentes na água da chuva da Ilha Grande. Valores calculados com base nas concentrações médias ponderadas pelo volume e em unidade molar

Relações binárias entre os íons $\mathrm{Cl}^{-}, \mathrm{Na}^{+}, \mathrm{Mg}^{2+}, \mathrm{Ca}^{2+} \mathrm{e} \mathrm{SO}_{4}^{2-}$ foram altamente significativas ( $\mathrm{p}<0,01 ; \mathrm{n}=20$ ), apresentando valores de $r$ na faixa de 0,94 a 1,00. Estes resultados sugerem a forte influência dos aerossóis de sal marinho ("sea-salt aerosols") na composição química da água da chuva, uma vez que estes íons representam os principais constituintes iônicos da água do $\operatorname{mar}^{14}$. Os ventos do quadrante sul, predominantes na região ${ }^{22}$, são responsáveis pelo transporte, em direção ao continente, dos aerossóis de sal marinho.

Partindo-se da premissa que, em áreas costeiras, todo $\mathrm{o} \mathrm{Na}^{+}$ presente na água da chuva tem como origem exclusiva a água do mar $^{3,23,24}$, é possível estimar a parcela de origem marinha dos íons $\mathrm{Cl}^{-}, \mathrm{Mg}^{2+}, \mathrm{Ca}^{2+}, \mathrm{K}^{+}$e $\mathrm{SO}_{4}^{2-}$ por meio da Equação 7

$[\mathrm{X}]_{\text {mar }}=\left\{[\mathrm{X}] /\left[\mathrm{Na}^{+}\right]\right\}_{\text {mar }} \times\left[\mathrm{Na}^{+}\right]_{\text {analisado }}$

onde X representa o íon $\mathrm{Cl}^{-}, \mathrm{Mg}^{2+}, \mathrm{Ca}^{2+}, \mathrm{K}^{+}$ou $\mathrm{SO}_{4}^{2-},[\mathrm{X}]_{\text {mar }}$ é a concentração de um desses íons determinada na água da chuva e cuja origem é atribuída à água do mar, $\left\{[\mathrm{X}] /\left[\mathrm{Na}^{+}\right]\right\}_{\operatorname{mar}}$ é a razão entre as concentrações dos íons $\mathrm{X}$ e $\mathrm{Na}^{+}$na água do $\operatorname{mar}^{14}$, e $\left[\mathrm{Na}^{+}\right]_{\text {nalisado }}$ corresponde à concentração do íon $\mathrm{Na}^{+}$determinada na água da chuva. Vale ressaltar que os valores de $\left\{[\mathrm{X}] /\left[\mathrm{Na}^{+}\right]\right\}_{\text {mar }}$ dependem da unidade utilizada para expressar as concentrações dos íons em questão.

A diferença entre a concentração do íon $\mathrm{X}$ determinada na água da chuva, designada por $[\mathrm{X}]_{\text {total }}$, e a concentração atribuída à água do mar, $[\mathrm{X}]_{\operatorname{mar}}$, fornece a concentração do íon X oriunda de outras fontes (naturais e/ou antrópicas), representada na Equação 8 por $[\mathrm{X}]_{\text {excesso }}$ :

$[\mathrm{X}]_{\text {excesso }}=[\mathrm{X}]_{\text {total }}-[\mathrm{X}]_{\mathrm{mar}}$

As estimativas dos excessos dos íons $\mathrm{Cl}^{-}, \mathrm{Mg}^{2+}, \mathrm{Ca}^{2+}, \mathrm{K}^{+}$e $\mathrm{SO}_{4}^{2-}$ na água da chuva da Ilha Grande foram, em média, respectivamente $7,20,32,56$ e $51 \%$. Portanto, os três primeiros íons tiveram como fonte principal os aerossóis de sal marinho. Os excessos de $\mathrm{Mg}^{2+}, \mathrm{Ca}^{2+}$ e principalmente $\mathrm{K}^{+}$devem ter como origem os aerossóis solúveis procedentes da vegetação abundante na Ilha Grande e na serra do Mar, nos arredores das baías da Ilha Grande e Sepetiba. Metade do $\mathrm{SO}_{4}^{2-}$ total presente na água da chuva da Ilha Grande representa excesso de sulfato (doravante abreviado por exc- $\mathrm{SO}_{4}^{2-}$ ). A parcela de exc- $\mathrm{SO}_{4}{ }^{2-}$ estimada em águas de chuva de algumas localidades do Brasil, litorâneas ou não, encontra-se, em geral, na faixa de 65 a quase $100 \%$ do $\mathrm{SO}_{4}{ }^{2-}$ total ${ }^{3,5,6,17,24,25}$. Pela localização de nossa área de estudo, as possíveis origens do exc- $\mathrm{SO}_{4}{ }^{2-}$ seriam a queima de combustíveis fósseis e o sulfeto de dimetila $\left(\mathrm{CH}_{3} \mathrm{SCH}_{3}\right)$ emitido da superfície do mar. Entretanto, verifica-se que o limite superior das concentrações MPV de exc- $\mathrm{SO}_{4}{ }^{2-}$ em águas de chuva de regiões remotas (oceânicas e continentais) é de aproximadamente $2,5 \mu \mathrm{mol} \mathrm{L} \mathrm{L}^{-1,21,26}$. Portanto, acredita-se que o exc- $\mathrm{SO}_{4}{ }^{2-}$ na água da chuva da Ilha Grande, cuja concentração MPV corresponde a $8,8 \mu \mathrm{mol} \mathrm{L} \mathrm{L}^{-1}$, origine-se predominantemente de fontes antrópicas, em especial os processos que envolvem queima de combustíveis fósseis.

Uma característica interessante da composição química da água da chuva na Ilha Grande é a razão $\mathrm{NH}_{4}^{+} / \mathrm{NO}_{3}^{-}$, que, com base nas concentrações MPV, é 0,8 . Este valor difere do que tem sido verificado para a razão $\mathrm{NH}_{4}^{+} / \mathrm{NO}_{3}^{-}$em águas de chuva nas regiões metropolitanas do Rio de Janeiro (RMRJ) e de São Paulo (RMSP), onde os valores encontram-se na faixa de 1,2 a 2,2 20,24,27,28. Isso pode ser atribuído a uma combinação de fatores, tais como, a característica insular da área de estudo, a predominância de ventos do quadrante sul e, principalmente, a ausência de fontes significativas de $\mathrm{NH}_{3}$ nas proximidades. $\mathrm{A} \mathrm{NH}_{3}$ não participa expressivamente de reações fotoquímicas ${ }^{2}$ e seu principal papel na atmosfera urbana é a neutralização dos ácidos $\mathrm{H}_{2} \mathrm{SO}_{4}$ e $\mathrm{HNO}_{3}$, produtos da oxidação dos gases $\mathrm{SO}_{2}$ e $\mathrm{NO}_{\mathrm{x}}\left(\mathrm{NO}+\mathrm{NO}_{2}\right)$, dando origem a sais de amônio $\left[\mathrm{NH}_{4} \mathrm{HSO}_{4},\left(\mathrm{NH}_{4}\right)_{2} \mathrm{SO}_{4}\right.$ e $\left.\mathrm{NH}_{4} \mathrm{NO}_{3}\right]$ que ocorrem predominantemente associados à faixa de partículas finas (diâmetro aerodinâmico $<2,5 \mu \mathrm{m}$ ) e podem ser transportadas a longas distânci$\mathrm{as}^{2}$. Portanto, estas partículas podem ter como procedência as emissões antrópicas de áreas situadas a centenas ou milhares de quilômetros de distância ${ }^{29-31}$.

No caso da RMRJ, localizada a nordeste da Ilha Grande, as potenciais fontes antrópicas emissoras de amônia $\left(\mathrm{NH}_{3}\right)$ para a atmosfera são os sistemas de esgotamentos sanitários, rios e canais receptores de grandes quantidades de esgotos não tratados, depósitos de lixo e aterros sanitários, veículos ${ }^{32}$ e queima de biomassa no período de estiagem ${ }^{33}$. No Brasil, não há inventários de fontes emissoras de $\mathrm{NH}_{3}$, tanto para o ambiente urbano quanto rural. Recentemente, Guimarães e de Mello ${ }^{34}$ mostraram que as concentrações de nitrogênio amoniacal $\left(\mathrm{NH}_{\mathrm{x}}=\mathrm{NH}_{4}^{+}+\mathrm{NH}_{3}\right)$ nas águas superficiais da baía de Guanabara, em especial as do setor noroeste da baía, 
são suficientemente elevadas para promoverem a emissão de $\mathrm{NH}_{3}$ para a atmosfera. No caso da baía de Sepetiba, localizada a nordeste da Ilha Grande, Tenório ${ }^{35}$ encontrou concentrações médias mensais de $\mathrm{NH}_{\mathrm{x}}\left(0,1\right.$ e $1,0 \mu \mathrm{mol} \mathrm{\textrm {L } ^ { - 1 } )}$ muito inferiores às verificadas por Guimarães e de Mello ${ }^{34}$ na baía de Guanabara $\left(2\right.$ e $\left.143 \mu \mathrm{mol} \mathrm{L}{ }^{-1}\right)$. Sendo assim, na condição de ventos de nordeste, a baía de Sepetiba muito pouco ou nada contribuiria em termos de emissão de $\mathrm{NH}_{3}$ para a atmosfera. Para ventos oriundos do quadrante sul, o mesmo se espera no que diz respeito às águas superficiais do Atlântico, visto que as concentrações de $\mathrm{NH}_{\mathrm{x}}$ em águas oceânicas tendem a ser inferiores a $0,1 \mu \mathrm{mol} \mathrm{L} \mathrm{L}^{-1} 36$.

\section{Fluxos de deposições úmida, seca e total}

A Tabela 2 apresenta as matrizes dos fatores de carga após a rotação VARIMAX para as amostras de deposição úmida e seca. Os resultados da análise de componentes principais para as amostras de deposição úmida mostram 3 fatores e para deposição seca 2 fatores que explicam, respectivamente, 88 e $77 \%$ da variabilidade total dos dados. Para a deposição úmida, o fator 1 apresenta cargas significativas na faixa de 0,94 a 0,98 para as variáveis condutividade, $\mathrm{Na}^{+}, \mathrm{Ca}^{2+}, \mathrm{Mg}^{2+}, \mathrm{SO}_{4}^{2-}$ e $\mathrm{Cl}^{-}$. Sessenta e sete por cento da variância do sistema são explicadas neste fator, que claramente está relacionado aos aerossóis de sal marinho como origem principal destes íons. $\mathrm{O}$ fator 2 apresenta carga (negativa) significativa para $\mathrm{H}^{+}$, explicando quase $12 \%$ da variância do sistema. O fator 3 apresenta cargas significativas, com sinais inversos, para a precipitação acumulada e $\mathrm{NO}_{3}^{-}$, correspondendo a $10 \%$ da variância do sistema.

Tabela 2. Fatores de carga após a rotação VARIMAX para as amostras de deposição úmida $(\mathrm{n}=20)$ e deposição seca $(\mathrm{n}=23)$

\begin{tabular}{lrrrrr}
\hline & \multicolumn{3}{c}{ Deposição Úmida } & \multicolumn{2}{c}{ Deposição Seca } \\
& Fator 1 & Fator 2 & Fator 3 & Fator 1 & Fator 2 \\
\hline Precipitação (mm) & $-0,03$ & 0,31 & $-0,83$ & - & - \\
Condutividade & 0,97 & 0,01 & 0,22 & 0,98 & 0,02 \\
$\left(\mu \mathrm{S} \mathrm{cm}^{-1}\right)$ & & & & & \\
$\mathrm{H}^{+}$ & 0,10 & $-0,90$ & 0,14 & $-0,24$ & 0,70 \\
$\mathrm{NH}_{4}^{+}$ & 0,45 & 0,55 & 0,55 & 0,22 & 0,59 \\
$\mathrm{Na}^{+}$ & 0,98 & $-0,00$ & 0,14 & 0,94 & 0,12 \\
$\mathrm{~K}^{+}$ & 0,82 & $-0,07$ & 0,12 & 0,83 & 0,37 \\
$\mathrm{Ca}^{2+}$ & 0,96 & 0,09 & 0,23 & 0,92 & 0,14 \\
$\mathrm{Mg}^{2+}$ & 0,97 & 0,10 & 0,18 & 0,93 & 0,01 \\
$\mathrm{NO}_{3}^{-}$ & 0,50 & 0,20 & 0,72 & 0,42 & 0,62 \\
$\mathrm{SO}_{4}^{2-}$ & 0,94 & $-0,05$ & 0,24 & 0,86 & 0,24 \\
$\mathrm{Cl}^{-}$ & 0,97 & 0,08 & 0,18 & 0,98 & 0,09 \\
Altovalor $^{\text {Variância }}$ & 7,40 & 1,26 & 1,13 & 6,44 & 1,21 \\
explicada (\%) & 67,0 & 11,5 & 10,0 & 64,5 & 12,1 \\
\hline
\end{tabular}

Para a deposição seca, o fator 1 mostra cargas significativas na faixa de 0,92 a 0,98 para condutividade, $\mathrm{Na}^{+}, \mathrm{Ca}^{2+}, \mathrm{Mg}^{2+}$ e $\mathrm{Cl}^{-}$. Cerca de $65 \%$ da variância desse sistema é explicada neste fator, sugerindo a forte influência dos aerossóis de sal marinho. $\mathrm{O}$ fator 2 também apresenta carga significativa para $\mathrm{H}^{+}$, sugerindo uma pos-

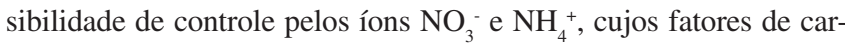
ga foram, respectivamente, 0,62 e 0,59 .

A Tabela 3 apresenta os resultados dos fluxos de deposição úmida e deposição seca, juntamente com os valores relativos desta distribuição para os diferentes íons. Vale ressaltar que os fluxos de deposição (úmida e seca) foram calculados com base em 192 dias, período no qual todos os eventos de chuva foram coletados, o que corresponde a cerca de $53 \%$ do total de dias do ano. Neste período o total de chuva acumulada foi de $535 \mathrm{~mm}$, o que corresponde a $37 \%$ da precipitação média anual na Ilha Grande. O período estudado correspondeu predominantemente às estações de outono e inverno. Sendo assim, optou-se pela apresentação dos fluxos em mol ha ${ }^{-1}$ mês $^{-1}$. Tanto na deposição úmida quanto na seca, os 5 íons mais abundantes decresceram na seguinte ordem: $\mathrm{Cl}^{-}>\mathrm{Na}^{+}>\mathrm{Mg}^{2+}$ $>\mathrm{SO}_{4}^{2-}>\mathrm{NO}_{3}^{-}$.

Tabela 3. Fluxos de deposição úmida e seca (em mol ha-1 mês $\left.{ }^{-1}\right)^{*}$ na costa sul da Ilha Grande - valores em parênteses expressam os percentuais da contribuição para a deposição total

\begin{tabular}{lrrr}
\hline & Deposição Úmida & Deposição Seca & Deposição Total \\
\hline $\mathrm{H}^{+}$ & $5,1(97 \%)$ & $0,2(3 \%)$ & 5,3 \\
$\mathrm{Na}^{+}$ & $120,6(53 \%)$ & $106,4(47 \%)$ & 226,0 \\
$\mathrm{~K}^{+}$ & $6,0(59 \%)$ & $4,1(42 \%)$ & 10,1 \\
$\mathrm{Mg}^{2+}$ & $17,1(56 \%)$ & $13,5(44 \%)$ & 30,6 \\
$\mathrm{Ca}^{2+}$ & $3,9(48 \%)$ & $4,3(52 \%)$ & 8,2 \\
$\mathrm{NH}_{4}^{+}$ & $8,4(90 \%)$ & $0,9(10 \%)$ & 9,3 \\
$\mathrm{NO}_{3}^{-}$ & $10,1(57 \%)$ & $7,7(43 \%)$ & 17,8 \\
$\mathrm{SO}_{4}^{2-}$ & $14,8(50 \%)$ & $14,9(50 \%)$ & 29,7 \\
$\mathrm{Cl}^{-}$ & $151,1(53 \%)$ & $133,8(47 \%)$ & 284,9
\end{tabular}

$* 1 \mathrm{ha}=10^{4} \mathrm{~m}^{2}$.

Os fluxos de deposição úmida foram, em geral, superiores aos de deposição seca. A deposição úmida representou de 48 a $97 \%$ da deposição total. Os íons predominantemente associados à deposição úmida foram $\mathrm{NH}_{4}^{+}(90 \%)$ e $\mathrm{H}^{+}(97 \%)$. No caso do íon $\mathrm{NH}_{4}^{+}$isto se explica em virtude da alta solubilidade do gás $\mathrm{NH}_{3}\left(K_{\mathrm{H}}=57,6 \mathrm{~mol} \mathrm{~L}^{-1}\right.$ atm $^{-1}$ a $\left.25^{\circ} \mathrm{C}\right)^{16}$ e de sua capacidade de ionização em meio aquoso $\left[\mathrm{NH}_{3}(\mathrm{aq})+\mathrm{H}^{+} \rightarrow \mathrm{NH}_{4}^{+} ; k_{\mathrm{a}}=3,2 \times 10^{10} \mathrm{~mol} \mathrm{~L}^{-1}\right]^{16}$. Na faixa de $\mathrm{pH}$ normalmente verificada para águas de chuva $(\mathrm{pH}=4,0-6,0)$, a maior parte do $\mathrm{NH}_{x}$ encontra-se ionizado, i.e., como $\mathrm{NH}_{4}^{+}$. O íon $\mathrm{H}^{+}$é resultante do equilíbrio ácido-base na água da chuva. Nas regiões continentais tropicais e subtropicais, naturais ou sob influência das atividades antrópicas, as principais substâncias responsáveis pelo controle das concentrações do íon $\mathrm{H}^{+}$na água da chuva são $\mathrm{H}_{2} \mathrm{SO}_{4}, \mathrm{HNO}_{3}$, $\mathrm{HCOOH}, \mathrm{CH}_{3} \mathrm{COOH}$ e $\mathrm{NH}_{3}{ }^{4,18,20,26}$. No caso da deposição seca na Ilha Grande, as soluções obtidas de sua solubilização em água forneceram valores de $\mathrm{pH}$ entre 5,7 e 6,8.

É importante salientar que valores de deposição seca medidos através da técnica aplicada neste trabalho não necessariamente expressam a totalidade transferida dos íons estudados da atmosfera para a superfície. A razão disso é que a deposição seca, além de outros fatores, depende muito das características da superfície de deposição (água, vegetação, solo ou rocha) ${ }^{37,38}$. De Mello et al. ${ }^{39}$ mostram que os fluxos de deposição seca sobre superfícies de materiais secos e sobre a superfície de água pura variaram de íon para íon, sendo que, em todos os casos, os fluxos foram superiores sobre a superfície de água, ou seja, a razão (fluxo sobre água)/(fluxo sobre superfícies secas) variou de 1,1 a 1,3 para os íons $\mathrm{Cl}^{-}$e $\mathrm{Na}^{+}$, de 1,7 a 2,5 para os íons $\mathrm{NO}_{3}^{-}, \mathrm{K}^{+}, \mathrm{Mg}^{2+}$ e $\mathrm{Ca}^{2+}$, e foi 6,0 para o íons $\mathrm{SO}_{4}{ }^{2-}$.

\section{CONCLUSÕES}

Durante o período de estudo na Ilha Grande, o pH da água de chuva variou de 4,34 a 6,30, com MPV de 5,22, correspondendo a

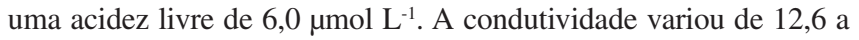
$222 \mu \mathrm{S} \mathrm{cm}^{-1} \mathrm{e}$ em média as concentrações iônicas, em unidade molar, decresceram na seguinte ordem: $\mathrm{Cl}^{-}>\mathrm{Na}^{+}>\mathrm{Mg}^{2+}>\mathrm{SO}_{4}{ }^{2-}>\mathrm{NO}_{3}{ }^{-}$ 
$\sim \mathrm{NH}_{4}^{+}>\mathrm{K}^{+} \sim \mathrm{H}^{+}>\mathrm{Ca}^{2+}$. Na água da chuva, as estimativas dos excessos, em relação às parcelas procedentes do aerossol de sal marinho, foram: $\mathrm{Cl}^{-}(7 \%), \mathrm{Mg}^{2+}(20 \%), \mathrm{Ca}^{2+}(32 \%), \mathrm{K}^{+}(56 \%) \mathrm{e}$ $\mathrm{SO}_{4}^{2-}(51 \%)$.

O fluxo de deposição de $\mathrm{NO}_{3}^{-}$foi superior ao de $\mathrm{NH}_{4}^{+}$, o inverso do que se verifica em outras localidades do estado do Rio de Janeiro e Sudeste do Brasil, o que possivelmente se deve às baixas emissões de $\mathrm{NH}_{3}$ do oceano e também das baías de Sepetiba e da Ilha Grande. No período estudado, os fluxos de deposição total (úmida + seca) de $\mathrm{NH}_{4}^{+}, \mathrm{NO}_{3}^{-}$e exc- $\mathrm{SO}_{4}{ }^{2-}$ na Ilha Grande foram estimados em 9,3 mol ha ${ }^{-1}$ ês $^{-1}\left(130 \mathrm{~g} \mathrm{NH}_{4}^{+}-\mathrm{N} \mathrm{ha}^{-1}\right.$ mês $\left.^{-1}\right), 17,8$ mol ha ${ }^{-1}$ mês $^{-1}$ (249 $\mathrm{g} \mathrm{NO}_{3}^{-}-\mathrm{N}^{-1} \mathrm{mês}^{-1}$ ) e 16,0 mol ha ${ }^{-1}$ mês $^{-1}$ (512 g S ha- mês $\left.^{-1}\right)$.

\section{AGRADECIMENTOS}

Ao Conselho Nacional de Desenvolvimento Científico e Tecnológico (CNPq), pelo apoio financeiro concedido aos projetos 521907/96-9 e 474113/2003-5, e ao Fundo Nacional do Meio Ambiente (FNMA), pelo apoio financeiro concedido ao projeto "Deposições Atmosféricas" ( $n^{\circ}$ 1108/94). Os agradecimentos se estendem a G. Sette, pela imprescindível colaboração na coleta, estocagem e no transporte das amostras.

\section{REFERÊNCIAS}

1. Seinfeld, J. H.; Atmospheric Chemistry and Physics of Air Pollution, John Wiley \& Sons: New York, 1986.

2. Finlayson-Pitts, B. J.; Pitts, J. N.; Chemistry of the Upper and Lower Atmosphere, Academic Press: New York, 2000.

3. de Mello, W. Z.; Ciência e Cultura 1988, 40, 1008.

4. Williams, M. R.; Fisher, T. R.; Melack, J. M.; Atmos. Environ. 1997, 31, 207.

5. Almeida, M. D.; Dissertação de Mestrado, Universidade Federal Fluminense, Brasil, 2001.

6. de Mello, W. Z.; Almeida, M. D.; Environ. Pollut. 2004, 129, 63.

7. Jickells, T. D.; Science 1998, 281, 217.

8. Matson, P. A.; McDowell, W. H.; Townsend, A. R.; Vitousek, P. M.; Biogeochemistry 1999, 46, 67.

9. Pedlowisky, M. A.; Lacerda, L. D.; Ovalle, A. R. C.; Watts, P. P.; Silva Filho, E. V.; Ciência e Cultura 1991, 43, 380; Pedlowisky, M. A.; Lacerda, L. D.; Ovalle, A. R. C.; Silva Filho, E. V.; Grille, F. S. S.; VII Congresso Brasileiro de Meteorologia, São Paulo, Brasil, 1992; de Mello, W. Z.; Proceedings of the International Simposium on Perspective for Environmental Geochemistry in Tropical Countries, Niterói, Brasil, 1993; Silva Filho, E. V.; Tese de Doutorado, Universidade Federal Fluminense, Brasil, 1997; Oliveira, R. R.; Tese de Doutorado, Universidade Federal do Rio de Janeiro, Brasil, 1999.

10. Maldonado, J.; Dissertação de Mestrado, Universidade Estadual do Rio de Janeiro, Brasil, 2003.

11. Galloway, J. N.; Likens, G. E.; Tellus 1978, 30, 71.

12. Karlsson, V.; Laurén, M.; Peltoniemi, S.; Atmos. Environ. 2000, 34, 4859.

13. Eaton, A. D.; Clesceri, L. S.; Greenberg, A. E.; Standard Methods for the Examination of Water and Wastewater, American Public Health Association: Washington, 1995.
14. Riley, J. P.; Chester, R.; Introduction to Marine Chemistry, Academic Press: London, 1971, p. 465.

15. Weast, R. C.; Astle, M. J.; Beyer, W. H.; Handbook of Chemistry and Physics, CRC Press: Boca Raton, 1985.

16. Stumm, W.; Morgan, J. J.; Aquatic Chemistry - An Introduction Emphasizing Chemical Equilibria in Natural Waters, John Wiley \& Sons: New York, 1981.

17. Campos, V. P.; Costa, A. C. A.; Tavares, T. M.; Quim. Nova 1998, 21, 418.

18. Andreae, M. O.; Talbot, R. W.; Berresheim, H.; Beecher, K. M.; J. Geophys. Res. 1990, 95, 16987; Lacaux, J. P.; Delmas, R.; Kouadio, G.; Cros, B.; Andreae, M. O.; J. Geophys. Res. 1992, 97, 6195.

19. Kieber, R. J.; Peake, B.; Willey, J. D.; Avery, G. B.; Atmos. Environ. 2002, $36,3557$.

20. Fornaro, A.; Gutz, I. G. R.; Atmos. Environ. 2003, 37, 117; Leal, T. F. M.; Fontenele, A. P. G.; Pedrotti, J. J.; Fornaro, A.; Quim. Nova 2004, 27, 855.

21. Galloway, J. N.; Likens, G. E.; Keene, W. C.; Miller, J. M.; J. Geophys. Res. 1982, 87, 8771.

22. FIDERJ - Fundação Instituto de Desenvolvimento Econômico e Social do Rio de Janeiro; Indicadores Climatológicos, Governadoria do Estado do Rio de Janeiro/Secretaria de Planejamento e Coordenação Geral, Rio de Janeiro, 1978.

23. Keene, W. C.; Pszenny, A. A. P.; Galloway, J. N.; Hawley, M. E.; J. Geophys. Res. 1986, 91, 6647

24. de Mello, W. Z.; Environ. Pollut. 2001, 114, 235.

25. Migliavacca, D. M.; Teixeira, E. C.; Machado, A. C. M.; Pires, M. R.; Quim. Nova 2005, 28, 371.

26. Galloway, J. N.; Keene, W. C.; Likens, G. E.; J. Geophys. Res. 1996, 101, 6883.

27. de Mello, W. Z.; Resumos do IX Congresso Brasileira de Geoquímica, Belém, Brasil, 2003.

28. Rocha, F. R.; Fracassi da Silva, J. A.; Lago, C. L.; Fornaro, A.; Gutz, I. G. R.; Atmos. Environ. 2003, 37, 105.

29. Tanner, R. L.; Parkhurst, W. J.; Valente, M. L.; Humes, K. L.; Jones, K.; Gilbert, J.; Atmos. Environ. 2001, 35, 6539.

30. Zunckel, M.; Saizar, C.; Zarauz, J.; Atmos. Environ. 2003, 37, 1601.

31. http://www.cptec.inpe.br/meio_ambiente, acessada em Junho 2005.

32. Fraser, M. P.; Cass, G. R.; Environ. Sci. Technol. 1998, 32, 1053; Kean, A J.; Harley, R. A.; Littlejohn, D.; Kendall, G. R.; Environ. Sci. Technol. 2000, 34, 3535; Perrino, C.; Catrambone, M.; Di Menno Di Bucchianico, A.; Allegrini, I.; Atmos. Environ. 2002, 36, 5385.

33. Heqq, D. A.; Radke, L. F.; Hobbs, P. V.; Riggan, P. J.; Geophys. Res. Lett. 1988, 15, 335; Heqq, D. A.; Radke, L. F.; Hobbs, P. V.; Rasmussen, R. A.; Riggan, P. J.; J. Geophys. Res. 1990, 95, 569; Akeredolu, F.; Isichei, A. O. Em Global Biomass Burning - Atmospheric, Climatic, and Biospheric Implications; Levine, J. S., ed.; The MIT Press: Cambridge, 1991, cap. 21, p. 162; Lacaux, J. P.; Delmas, R. A.; Cros, B.; Lefreive, B.; Andreae, M. O. Em Global Biomass Burning - Atmospheric, Climatic, and Biospheric Implications, Levine, J. S., ed.; The MIT Press: Cambridge, 1991, cap. 22, p. 167; Olivier, J. G. J.; Bouwman, A. F.; Van der Hoek, K. W.; Berdowski, J. J. M.; Environ. Pollut. 1998, 102, 135.

34. Guimarães, G. P.; de Mello, W. Z.; Quim. Nova 2006, 29, 54.

35. Tenório, M. M. B.; Dissertação de Mestrado, Universidade Santa Úrsula, Brasil, 1999.

36. Quinn, P. K.; Barret, K. J.; Dentener, F. J.; Lipschultz, F.; Six, K. D.; Biogeochemistry 1996, 35, 275.

37. Sehmel, G. A.; Atmos. Environ. 1980, 14, 983.

38. McMurry, P. H.; Atmos. Environ. 2000, 34, 1959; Wesely, M. L.; Hicks, B. B.; Atmos. Environ. 2000, 34, 2261.

39. de Mello, W. Z.; Souza, M. P.; Motta, J. S. T.; Ciência e Cultura 1987, 39, 1075 . 